
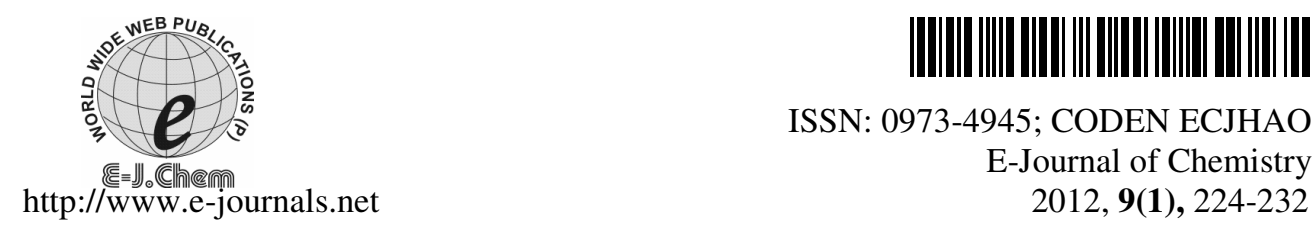

ISSN: 0973-4945; CODEN ECJHAO

E-Journal of Chemistry 2012, 9(1), 224-232

\title{
Simultaneous Determination of Eosin-Yellow and Ponceau-S Using $H$-Point Standard Addition Method in Micellar Media
}

\author{
AMANDEEP KAUR and USHA GUPTA* \\ Department of Chemistry \\ Punjabi University, Patiala- 147002, Punjab, India \\ guptausha57@yahoo.com
}

Received 9 June 2011; Accepted 12 August 2011

\begin{abstract}
H$-point standard addition method (HPSAM) is developed for simultaneous determination of eosin- $Y$ and ponceau- $s$ in micellar media. Nickel chloride $\left(\mathrm{NiCl}_{2}\right)$ is used as chromogenic reagent for complexes formation of eosin- $Y$ and ponceau- $S$ food colorants. The measurements were carried out using sodium lauryl sulphate as a surfactant, in buffered solution at $\mathrm{pH}$ 6.0. The concentration range of $0.115-2.53 \mu \mathrm{g} / \mathrm{mL}$ of eosin- $Y$ and $0.159-3.80 \mu \mathrm{g} / \mathrm{mL}$ of ponceau- $S$. The proposed procedures have been applied successfully for the simultaneous determination of eosin- $Y$ and ponceau- $S$ in synthetic binary mixtures and real samples.
\end{abstract}

Keywords: HPSAM, Eosin- $Y$, Ponceau- $S, \mathrm{NiCl}_{2}$, Sodium lauryl sulphate

\section{Introduction}

Food colorants can be applied to any dye, pigment or other substance artificially made or obtained from a vegetable, mineral, or another natural source. Colour ${ }^{1}$ is a vital constituent of food and probably the first characteristic perceived by the human senses. Food colouring ${ }^{2}$ is any substance that is added to food or drink to change its colour probably, for economic reasons. These dyes are used to supplement and enhance natural colours destroyed during processing or storage and substantially increase the appeal and acceptability of food stuffs ${ }^{3}$. Eosin $\mathrm{Y}^{4}$, a heterocyclic dye containing bromine atoms, is used in the fields of dyeing, printing, printing ink and fluorescent pigment, etc. Eosin $\mathrm{Y}$ is used in the dyeing industries because of its vivid colour. Traditional techniques, such as coagulation/flocculation, membrane separation (ultrafiltration, reverse osmosis) or absorption of activation carbon, are only based on a phase transfer of the pollutant. Biological methods are also ineffective to decolonization of eosin $\mathrm{Y}$ for its stability and complex aromatic structure ${ }^{5-7}$. The direct release of wastewater containing eosin $\mathrm{Y}$ will cause serious environmental problem due to its dark colour and toxicity ${ }^{8}$. 
Ponceau- $S$ dyes are anionic and used in the textile industry ${ }^{9}$ for dyeing of all natural fibres, e.g. wool, cotton, silk and synthetics, polyesters, acrylic and rayon. They are used in a variety of application fields such as in paints, inks, plastics. Ponceau- $S$ is used to prepare a stain for rapid reversible detection of protein ${ }^{10-11}$ bands on nitrocellulose, as well as on cellulose membranes. Ponceau- $S$ stain is easily reversed with water washes, facilitating subsequent immunological detection.

A modified equilibrium standard addition method called the " $H$-point standard addition method" (HPSAM) ${ }^{12-15}$ is developed for determination of unbiased ${ }^{16}$ analyte concentration in the event that the presence of direct interferent is known ${ }^{17-22}$. The method relies on the use of multipoint signal data to transform otherwise uncorrectable to correctable errors and evaluate the analyte and interferent concentration. The HPSAM has been applied with analytical spectroscopy to resolve mixtures of two components with extensively or fully overlapped spectra $^{23}$. By plotting the analytical signals versus added analytical concentration, two straight lines are obtained that have a common point $\mathrm{H}$ with coordinates $\left(\mathrm{C}_{\mathrm{H}}, \mathrm{A}_{\mathrm{H}}\right) ; \mathrm{C}_{\mathrm{H}}$ is the unknown analyte concentration and the $\mathrm{A}_{\mathrm{H}}$ is the analytical signal due to the interferent species.

Micelles posses a high potential for multicomponent analysis, which can be used as special reaction media because they alter the rate, equilibrium position ${ }^{24}$, products and stereochemistry of many reactions. In the metal-dye complex, at a concentration above critical micelle concentration micelles form a ternary complex with advantageous properties, such as hyper chromic and bath chromic shifts that can modify the sensitivity of the method by affecting the interferences and matrix effects ${ }^{25}$. The ability of micellar system to solublized slightly soluble or even insoluble complexes has been used to enhance the analytical merit of developed method ${ }^{26}$.

In this work, $H$-point standard addition method (HPSAM) was optimized for the simultaneous determination of eosin- $Y$ and ponceau- $S$ as $\mathrm{NiCl}_{2}$ complexes in a sodium lauryl sulphate micellar media at buffered $\mathrm{pH} 6.0$.

\section{Experimental}

All reagents used were of AnalaR grade unless otherwise stated. Double distilled water was used throughout. Stock solution of eosin- $Y$ and ponceau- $S$ (Loba chem.) were prepared in double distilled water respectively. A $1.0 \%$ (w/v) solution of $\mathrm{Ni}(\mathrm{II})$ was prepared by dissolving nickel chloride (Loba Chem.) in double distilled water. A buffer solution of $\mathrm{pH} 6.0$ was prepared by mixing appropriate amounts of $0.2 \mathrm{M}$ sodium acetate and $0.2 \mathrm{M}$ acetic acid solution. A $1.0 \%$ (w/v) sodium lauryl sulphate (SLS) stock solution was prepared in hot double distilled water.

Apparatus

Digitized UV-Vis absorption spectra were recorded using a Shimadzu 1700 spectrophotometer, with $10 \mathrm{~mm}$ quartz cell and measurements of $\mathrm{pH}$ were made with digital century $\left(\mathrm{C}_{\mathrm{p}}-\mathrm{901}\right) \mathrm{pH}$-meter using a combined glass electrode.

\section{Procedure}

\section{Individual calibration}

Appropriate volumes of eosin- $Y$ or ponceau- $S$ standard solutions (Beer`s law was obeyed in the concentration range of $0.115-2.53 \mu \mathrm{g} / \mathrm{mL}$ of eosin- $Y$ and $0.159-3.80 \mu \mathrm{g} / \mathrm{mL}$ of ponceau-S), $1.5 \mathrm{~mL}$ of $1.0 \%$ sodium lauryl sulphate (SLS), $2.0 \mathrm{~mL}$ of buffer solution (pH 6.0), $1.0 \mathrm{~mL}$ of $1.0 \% \mathrm{Ni}(\mathrm{II})$ solution were added into a $10.0 \mathrm{~mL}$ standard flask and volume was made up to the mark with double distilled water. A portion of the solution was transferred into a quartz cell and variations of absorbance were recorded for each sample. 


\section{Binary- HPSAM}

In a $10.0 \mathrm{~mL}$ standard flask, $1.5 \mathrm{~mL}$ of $1.0 \%$ sodium lauryl sulphate (SLS), $2.0 \mathrm{~mL}$ of buffer solution ( $\mathrm{pH} 7.0), 2.0 \mathrm{~mL}$ of $1.0 \% \mathrm{Ni}$ (II) (to ensure complete complexation when both eosin- $Y$ and ponceau- $S$ were present), appropriate amounts of eosin- $Y$ and ponceau- $S$ standard solutions in double distilled water were added. Absorbance of solution was measured at 522 and $512 \mathrm{~nm}$ (when standard solution of eosin- $Y$ was added) or 524 and $508 \mathrm{~nm}$ (when standard solution of ponceau- $S$ was added) against a reagent blank and graphs of absorbance $v s$ concentration were plotted. $\mathrm{C}_{\mathrm{H}}$ and $\mathrm{A}_{\mathrm{H}}$ were obtained from the point of intersection of the two derived straight lines.

\section{Results and Discussion}

HPSAM enables simultaneous determination of species $\mathrm{X}$ and $\mathrm{Y}$ in a mixture even if their analytical signals overlap extensively and their maxima are coinciding. Absorption spectra of eosin- $Y$ and ponceau- $S$ complexes with Ni(II) overlap as shown in Figure 1. Since the spectral bands of the two complexes overlaps. So, simultaneous determination of eosin- $Y$ and ponceau- $S$ food colorants is possible only using binary-HPSAM.

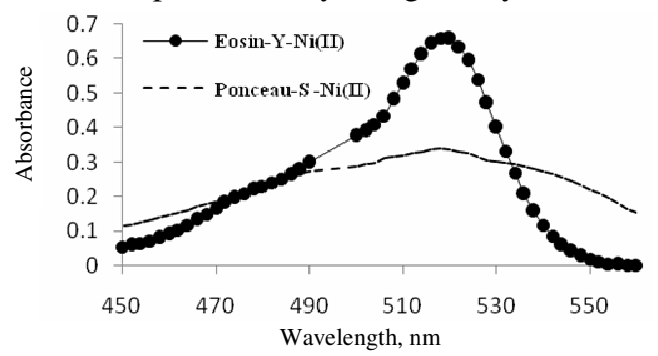

Figure 1. Absorption spectra of eosin- $Y$-Ni(II) and ponceau-S-Ni(II) complexes, in $1 \%$ SLS at $\mathrm{pH}$ 6.0.

\section{Optimization of variables}

Effect of $p H$

The effect of $\mathrm{pH}$ in the range of $3.5-9.5$ on absorbance of eosin- $Y-\mathrm{Ni}$ (II) and ponceau- $S-\mathrm{Ni}$ (II) is shown in Figure 2. Eosin- $Y-\mathrm{Ni}(\mathrm{II})$ and ponceau- $S-\mathrm{Ni}(\mathrm{II})$ complexes showed maximum absorbance at $\mathrm{pH} 6.0$.Therefore, $\mathrm{pH} 6.0$ was selected for simultaneous determination of eosin- $Y$ and ponceau- $S$.

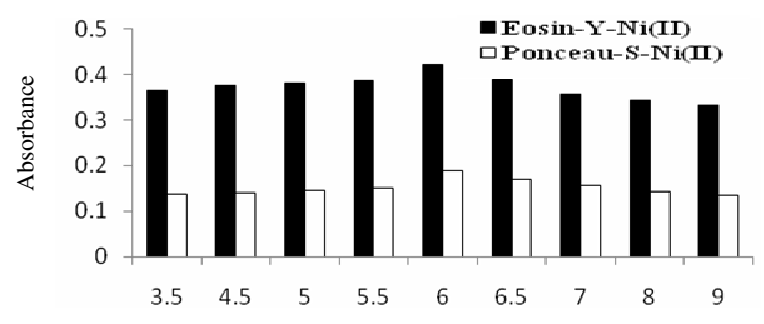

Figure 2. Effect of $\mathrm{pH}$ on the absorbance of eosin- $Y-\mathrm{Ni}$ (II) and ponceau-S-Ni(II) complex

\section{Effect of nature of the surfactant}

Various surfactants such as triton $\mathrm{x}-100$, tween-20, tween-80, cetylpyridinium bromide, cetyltrimethylammonium bromide and sodium lauryl sulphate were tried as solubilizing agents. Both for eosin- $Y$ and ponceau- $S$ complexes absorbance was maximum with sodium 
lauryl sulphate (SLS) as shown in Figure 3. So, for simultaneous determination of eosin- $Y$ and ponceau-S, $1.5 \mathrm{~mL}$ of $1.0 \%$ sodium lauryl sulphate (SLS) was selected as the working micellizing agent for further studies.

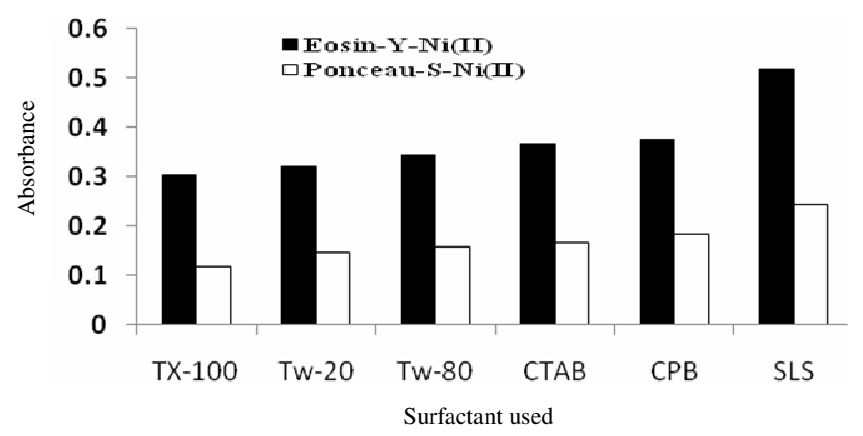

Figure 3. Effect of different surfactants on absorbance of Ni(II) complexes of eosin- $Y$ and ponceau- $S$

\section{Effect of reagent concentration}

Effect of different amounts of $\mathrm{Ni}(\mathrm{II})$ on the absorbance of eosin- $Y$-Ni(II) and ponceau- $S$ $\mathrm{Ni}(\mathrm{II})$ complexes was studied. The maximum absorbance in both the cases was observed when $1.0 \mathrm{~mL}$ of $1.0 \% \mathrm{Ni}$ (II) was used for individual calibration as shown in Figure 4. To ensure the complete complexation for simultaneous determination of eosin- $Y$ and ponceau-S, $2.0 \mathrm{~mL}$ of $1.0 \% \mathrm{Ni}$ (II) was used.

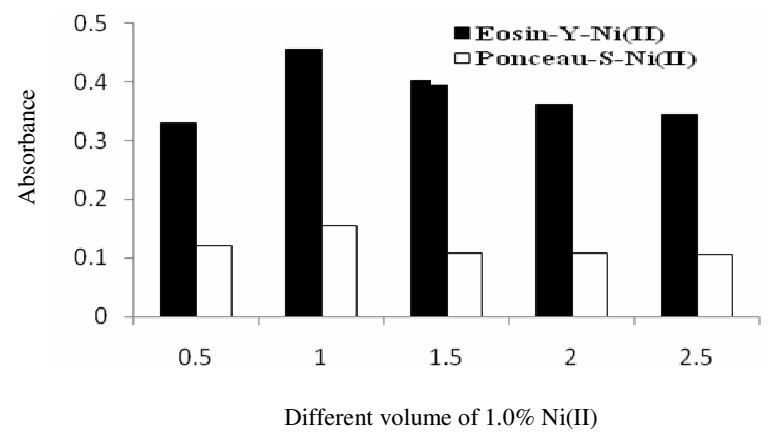

Figure 4. Effect of different amounts of $1 \% \mathrm{Ni}(\mathrm{II})$ on absorbance of eosin- $Y$ - Ni(II) and ponceau- $S-\mathrm{Ni}(\mathrm{II})$

\section{Applying binary - HPSAM}

When eosin- $Y$ is selected as the analyte, many pairs of wavelengths showing the same absorbance for the interferent i.e. Ponceau-S-Ni(II) complex were possible. When selecting one pair of wavelengths for obtaining good accuracy, the absorbance difference at the two selected wavelengths for eosin- $Y-\mathrm{Ni}$ (II) complex must be as large as possible. On the basis of the absorption spectra of eosin- $Y$ or ponceau- $S$ (as analyte), one of the best pairs of wavelength is 522 and 512 or 524 and $508 \mathrm{~nm}$, with these pairs of wavelength difference in absorbance and hence maximum sensitivity are attainable. The determination of $\operatorname{eosin}-Y$ and ponceau- $S$ in a series of samples containing fixed amounts of ponceau- $S$ with different amounts of eosin- $Y$ (Figure 5) or fixed amounts of eosin- $Y$ with different amounts of ponceau- $S$ (Figure 6) were carried out by adding eosin- $Y$ standard solutions. The applicability 
of HPSAM also tested for determination of ponceau- $S$ and eosin- $Y$ in a series of samples containing fixed amounts of ponceau- $S$ together with different amounts of eosin- $Y$ (Figure 7) or fixed amounts of eosin- $Y$ together with different amounts of ponceau- $S$ (Figure 8 ) were carried out by adding ponceau- $S$ standard solutions. The results show that ponceau-S and eosin- $Y$ contents in the samples could be determined accurately.

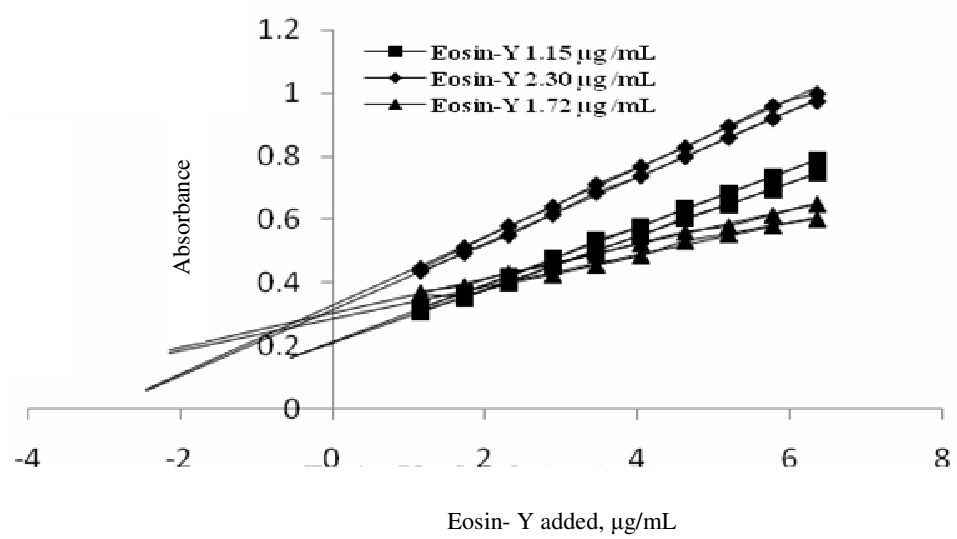

Figure 5. Plot of $H$-point standard addition method for simultaneous determination of fixed concentration of ponceau- $S 1.59 \mu \mathrm{g} / \mathrm{mL}$ and different concentration of eosin- $Y$, when different amounts of standard eosin- $Y$ solutions are added

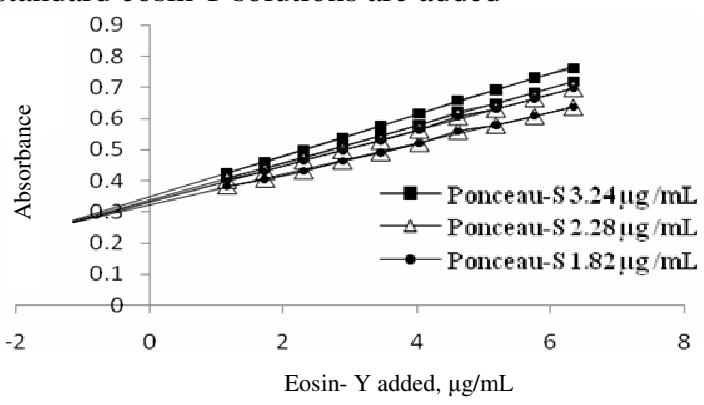

Figure 6. Plot of $H$-point standard addition method for simultaneous determination of fixed concentration of eosin-Y $1.38 \mu \mathrm{g} / \mathrm{mL}$ and different concentration of ponceau- $S$, when different amounts of standard eosin- $Y$ solutions are added

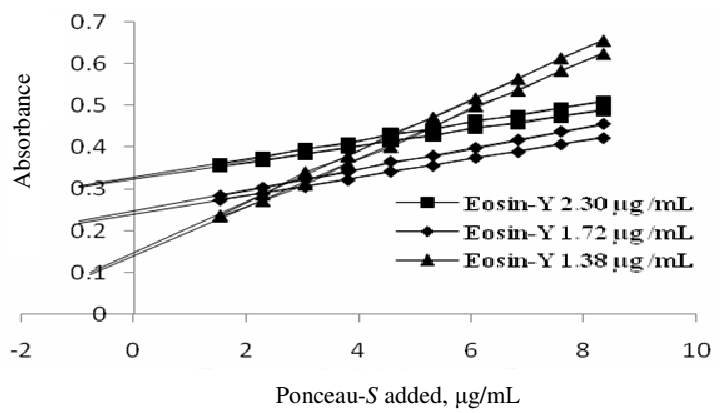

Figure 7. Plot of $H$-point standard addition method for simultaneous determination of fixed concentration of ponceau-S $2.02 \mu \mathrm{g} / \mathrm{mL}$ and different concentration of eosin- $Y$, when different amounts of standard ponceau-S solutions are added 


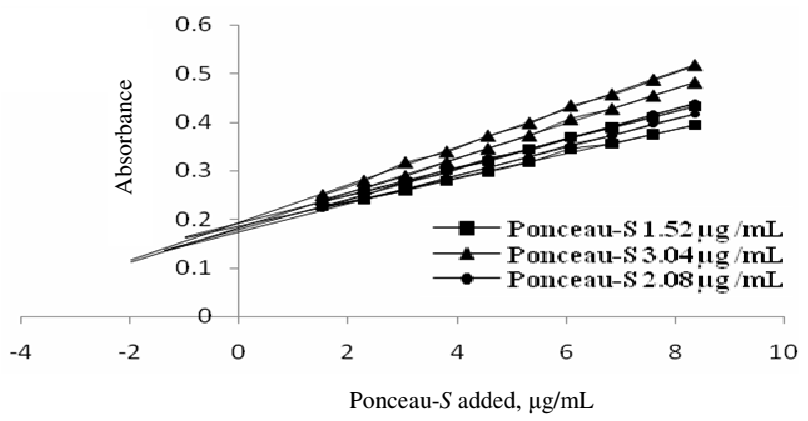

Figure 8. Plot of $H$-point standard addition method for simultaneous determination of fixed concentration of eosin- $Y 1.05 \mu \mathrm{g} / \mathrm{mL}$ and different concentration of ponceau- $S$, when different amounts of standard ponceau- $S$ solutions are added

\section{Reproducibility of the method}

Under optimum conditions simultaneous determination of eosin- $Y$ and ponceau- $S$ were made by using $H$-Point Standard addition method (HPSAM). To check the reproducibility of the method five replicate experiments were performed and the results are given in Table 1.

Table 1. Results of five replicate experiments for the analysis of eosin- $Y$ and ponceau- $S$ mixtures

\begin{tabular}{lccccc}
\hline \multicolumn{1}{c}{ A-C-Equation } & \multirow{2}{*}{$\mathrm{r}^{2}$} & \multicolumn{2}{c}{ Present, $\mu \mathrm{g} / \mathrm{mL}$} & \multicolumn{2}{c}{ Found, $\mu \mathrm{g} / \mathrm{mL}$} \\
& & Eosin- $Y$ & Ponceau- $S$ & Eosin- $Y$ & Ponceau- $S$ \\
\hline $\mathrm{A}_{524}=0.028 \mathrm{C}_{\mathrm{i}}+0.245$ & 0.999 & 2.10 & 1.63 & 2.05 & 1.61 \\
$\mathrm{~A}_{508}=0.024 \mathrm{C}_{\mathrm{i}}+0.237$ & 0.999 & & & & \\
$\mathrm{~A}_{524}=0.038 \mathrm{C}_{\mathrm{i}}+0.169$ & 0.998 & 2.10 & 1.63 & 2.05 & 1.61 \\
$\mathrm{~A}_{508}=0.035 \mathrm{C}_{\mathrm{i}}+0.163$ & 0.995 & & & & \\
$\mathrm{~A}_{524}=0.033 \mathrm{C}_{\mathrm{i}}+0.226$ & 0.996 & 2.10 & 1.63 & 2.08 & 1.61 \\
$\mathrm{~A}_{508}=0.030 \mathrm{C}_{\mathrm{i}}+0.218$ & 0.998 & & & & \\
$\mathrm{~A}_{524}=0.028 \mathrm{C}_{\mathrm{i}}+0.265$ & 0.997 & 2.10 & 1.63 & 2.08 & 1.62 \\
$\mathrm{~A}_{508}=0.024 \mathrm{C}_{\mathrm{i}}+0.254$ & 0.997 & & & & \\
$\mathrm{~A}_{524}=0.035 \mathrm{C}_{\mathrm{i}}+0.304$ & 0.995 & 2.10 & 1.63 & 2.08 & 1.62 \\
$\mathrm{~A}_{508}=0.031 \mathrm{C}_{\mathrm{i}}+0.292$ & 0.995 & & & & \\
Mean & & & & 2.07 & 1.61 \\
Standard deviation & & & & 0.01 & 0.007 \\
R.S.D, $\%$ & & & & 0.48 & 0.43 \\
LOD & & & & 0.03 & 0.021 \\
LOQ & & & & 0.1 & 0.07 \\
\hline
\end{tabular}

Accuracy and precision

Several synthetic samples with different concentration ratio of eosin- $Y$ and ponceau- $S$ were analyzed using HPSAM. The concentration ranges of eosin- $Y$ and ponceau- $S$ for construction of calibration graphs were $0.115-2.53$ and $0.159-3.80 \mu \mathrm{g} / \mathrm{mL}$ respectively. Several synthetic samples with different concentration ratios of eosin- $Y$ and ponceau- $S$ were analyzed using HPSAM. The results are given in Table 2. 
Table 2. Results of several experiments for the analysis of eosin- $Y$ and ponceau- $S$ in synthetic samples by $H$-point standard addition method (HPSAM)

\begin{tabular}{|c|c|c|c|c|c|c|c|}
\hline A-C Equation & $r^{2}$ & \multicolumn{2}{|c|}{$\begin{array}{c}\text { Present, } \mu \mathrm{g} / \mathrm{mL} \\
\text { Eosin- } Y \text {, Ponceau- } S\end{array}$} & \multicolumn{2}{|c|}{$\begin{array}{c}\text { Found, } \mu \mathrm{g} / \mathrm{mL} \\
\text { Eosin- } Y, \text { Ponceau- } S\end{array}$} & \multicolumn{2}{|c|}{$\begin{array}{c}\% \text { Recovery } \\
\text { Eosin-Y, Ponceau- } S\end{array}$} \\
\hline $\mathrm{A}_{522}=0.078 \mathrm{C}_{\mathrm{i}}+0.267$ & 0.999 & 166 & & 166 & 212 & 100 & 100 \\
\hline $\mathrm{A}_{512}=0.081 \mathrm{C}_{\mathrm{i}}+0.272$ & 0.999 & 1.06 & 2.12 & 1.60 & 2.12 & 100 & 100 \\
\hline $\mathrm{A}_{522}=0.065 \mathrm{C}_{\mathrm{i}}+0.414$ & 0.995 & 166 & 107 & 166 & 105 & 100 & 0898 \\
\hline $\mathrm{A}_{512}=0.068 \mathrm{C}_{\mathrm{i}}+0.419$ & 0.997 & 1.00 & 1.91 & 1.00 & 1.93 & 100 & 90.90 \\
\hline $\mathrm{A}_{522}=0.065 \mathrm{C}_{\mathrm{i}}+0.304$ & 0.998 & 2.00 & 1.67 & 2.00 & 1.66 & 100 & 99.40 \\
\hline $\mathrm{A}_{512}=0.071 \mathrm{C}_{\mathrm{i}}+0.316$ & 0.997 & 2.00 & $1.0 /$ & 2.00 & 1.00 & 100 & 99.40 \\
\hline$A_{522}=0.089 C_{i}+0.356$ & 0.999 & 2.00 & 2.49 & 2.00 & 2.49 & 100 & 100 \\
\hline $\mathrm{A}_{512}=0.094 \mathrm{C}_{\mathrm{i}}+0.366$ & 0.999 & 2.00 & 2.49 & 2.00 & 2.49 & & \\
\hline $\mathrm{A}_{522}=0.056 \mathrm{C}_{\mathrm{i}}+0.431$ & 0.965 & 2,42 & 2.73 & 2.33 & 2.71 & 96.28 & 99.26 \\
\hline $\mathrm{A}_{512}=0.062 \mathrm{C}_{\mathrm{i}}+0.445$ & 0.992 & 2.42 & 2.15 & 2.33 & 2.11 & & \\
\hline $\mathrm{A}_{522}=0.094 \mathrm{C}_{\mathrm{i}}+0.386$ & 0.995 & 2.53 & 2.73 & 2.50 & 2.72 & 98.81 & 99.63 \\
\hline $\mathrm{A}_{512}=0.100 \mathrm{C}_{\mathrm{i}}+0.401$ & 0.998 & 2.JJ & 2.15 & 2.00 & 2.12 & & \\
\hline $\mathrm{A}_{522}=0.068 \mathrm{C}_{\mathrm{i}}+0.447$ & 0.998 & 2.55 & & 2.50 & 2.57 & 98.03 & 99.61 \\
\hline $\mathrm{A}_{512}=0.072 \mathrm{C}_{\mathrm{i}}+0.457$ & 0.998 & 2.J5 & 2.58 & 2.00 & 2.01 & 90.05 & 99.01 \\
\hline $\mathrm{A}_{522}=0.085 \mathrm{C}_{\mathrm{i}}+0.429$ & 0.999 & 288 & 2.58 & 2.83 & 2.58 & 98.26 & 100 \\
\hline $\mathrm{A}_{512}=0.091 \mathrm{C}_{\mathrm{i}}+0.446$ & 0.993 & & 2.50 & 2.03 & & & \\
\hline
\end{tabular}

\section{Application}

Determination of eosin- $Y$ and ponceau-S in lipstick (fresh flower orange shade lipstick)

$1.0 \mathrm{~g}$ Sample (lipstick) was grounded in mortar with pestle and then digested with mixture of $\mathrm{HNO}_{3}: \mathrm{H}_{2} \mathrm{SO}_{4}$ taken in ratio of $(2: 1)$. The mixture was heated up to $100{ }^{\circ} \mathrm{C}$ for one hour and then cooled. After cooling $5 \mathrm{~mL}$ of double distilled water was added to the sample and mixed. The residue was filtered, diluted with double distilled water and made the volume up to mark in a standard volumetric flask. The sample solution was then analyzed by the developed procedure. The results are given in Table 3.

\section{Determination of eosin- $Y$ and ponceau-S in fruit jelly (orange flavour)}

$5.0 \mathrm{gm}$ of Fruit jelly was dissolved in hot double distilled water. After mixing, the residue was filtered, diluted with double distilled water up to mark in a standard volume. The sample solution was then analyzed by the developed procedure. The results are given in Table 3

Table 3. Determination of eosin- $Y$ and ponceau- $S$ in different samples by HPSAM

\begin{tabular}{ccccc}
\hline \multirow{2}{*}{ Sample } & \multicolumn{4}{c}{ Concentration, $\mu \mathrm{g} / \mathrm{mL}$} \\
\cline { 2 - 5 } & \multicolumn{2}{c}{ Present, $\mu \mathrm{g} / \mathrm{mL}$} & \multicolumn{2}{c}{ Found, $\mu \mathrm{g} / \mathrm{mL}$} \\
& Eosin- $Y$ & Ponceau- $S$ & Eosin- $Y$ & Ponceau- $S$ \\
\hline Lipstick & 1.32 & 1.52 & 1.35 & 1.56 \\
Fruit Jelly & 1.39 & 1.43 & 1.34 & 1.46 \\
Nail Enamel & 1.27 & 1.57 & 1.30 & 1.55 \\
Fruit Syrup & 1.43 & 1.31 & 1.46 & 1.33 \\
Cream Biscuit & 1.26 & 1.46 & 1.24 & 1.47 \\
\hline
\end{tabular}




\section{Determination of eosin- $Y$ and ponceau-S in nail paint (orange shifali nail enamel)}

$5.0 \mathrm{~mL}$ of Nail paint sample was mixed with $5.0 \mathrm{~mL}$ of ethanol. After mixing, the residue was filtered, diluted with double distilled water up to mark in $100.0 \mathrm{~mL}$ standard flask. The sample solution was then analyzed by the developed procedure. The results are given in Table 3.

\section{Determination of eosin-Y and ponceau-S in Fruit Syrup (orange fruit syrup)}

$20.0 \mathrm{~mL}$ of Double distilled water was mixed with $10.0 \mathrm{~mL}$ of fruit syrup. After mixing, the residue was filtered off and filtrate was diluted with double distilled water up to mark in $100.0 \mathrm{~mL}$ standard flask. The standard solution was analyzed by the developed procedure. The results are given in Table 3.

\section{Determination of eosin- $Y$ and ponceau-S in cream biscuit (orange flavour cream)}

$10.0 \mathrm{gm}$ of Cream sample was mixed with $20.0 \mathrm{~mL}$ of double distilled water. After mixing, the residue was filtered off and filtrate was diluted with double distilled water up to mark in $100.0 \mathrm{~mL}$ standard flask. The standard solution was analyzed by the developed procedure. The results are given in Table 3.

\section{Conclusion}

The important characteristic of this work are:

1. Simultaneous determination of eosin- $y$ and erythrosine without the use of any expensive instrument is achieved. This reduces the cost of applied method.

2. No extraction step is required as determination has been done in micellar media and hence the use of toxic and carcinogenic organic solvents is avoided. Most of the organic solvents that are being used for extraction are classified as toxic and environmental pollutants and some have been listed as carcinogenic by the US environmental protection agency (EPA).

\section{References}

1. Jeannine Delwiche, The impact of perceptual interactions on perceived flavour, Food Quality Preference, 2004, 15, 137-146.

2. Food additives and hyperactive behaviour in children in the community a randomized double blinded, placebo controlled trial, lancet, Sep 2007.

3. Branen A, Davidson P and Salminen S, Food additives, Academic New York, 1989.

4. Huaili Zheng, Yunxia Pan and Xinyi Xiang, J Photochemical, 2006.

5. Kositzi M, Antoniadis A, Poulios I, Kiridis I and Malato S, Solar Energy, 2004, 77(5), 591-600.

6. Perez M, Torrades F and Dom`enech X, J Pearl., 2002, 36, 2703-2710.

7. Xie Y, Chen F, He J, Jincai Z and Wang H, J Photochem Photobiology., 2000, A 136, 235-240.

8. Muruganandham M and Swaminathan M, Dyes Pigments, 2004, 63, 315-321.

9. Mohammad Reza Oversi, Mannan Hajin Mahmoodi and Fatemeh Davami, $D A R U, 2003, \mathbf{1 1}(\mathbf{1}), 1-6$.

10. Murray R K, Harper H W, Granner D K, Mayes P A and Rodwell V W, Lange Medical books/MC graw-Hill, 2006, 3, 146.

11. Jennifer Peterson, Sheldon Henderson, Stacy Henday, Bill Schrute, LC/GC Europe, 2008, 15. 
12. Bosch-Reig F and Campins-Falco P, Analyst, 1998, 113, 1011.

13. Bosch-Reig F and Campins-Falco P, Analyst, 1990, 115, 111.

14. Bosch-Reig F, Campins-Falco P and Verdu-Andres J, Talanta, 1992, 39, 1.

15. Bosch-Reig F, Campins-Falco P, Hernan-Dez B H and Sevilano-Cabeza A, Anal Chim Acta, 1992, 257, 89.

16. Bosch-Reig F, Verdu- Andres J, Campins-Falco P and Molins-legua C, Talanta, 1994, 41, 39-52.

17. Mannan Hajimahmoodi, J Food Anal Methods, 2008, 1, 214-219.

18. Eskandari H and Bagherian Dehaghi G, Microchim Acta, 2004, 146, 265.

19. Bosch-Reig F, Campins-Falco P, Sevillano-cabeza A, Herraez-Herhnandaz R and Molins-legua C, Anal Chem., 1991, 63, 2424.

20. Bosch-Reig F, Campins-Falco P and Verdu-Andres J, Anal Chem Acta, 1993, 283, 831-844.

21. Campins-Falco P, Bosch-Reig F and Verdu- Andres J, Anal Chem Acta, 1992b, 270, 253.

22. Campins-Falco P, Bosch-Reig F, Herraez-Heenan B, Sevilano-Cabeza A and Molinslegue C, Anal Chim Acta, 1995, 302,323.

23. Hund E, Massart D L and Smeyers-Varbeke J, J Pharm Biomed Anal., 1999, 21(1), 23-42.

24. Pearez-Bendito D and Rubio S, Trends Anal Chem., 1993, 12, 9-18.

25. Mclntire G L and Dorsey J G, Cri Rev Anal Chem., 1990, 21(4), 257-278.

26. Singh H B, Agnihotri N K and Singh V K, Talanta, 1999, 48(3), 623-631. 


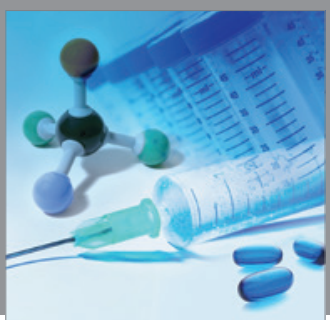

International Journal of

Medicinal Chemistry

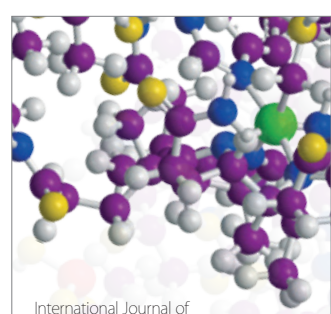

Carbohydrate Chemistry

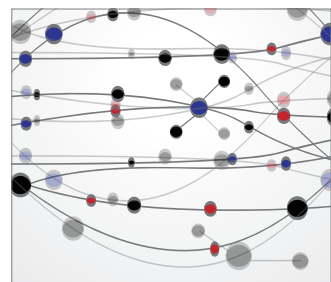

The Scientific World Journal
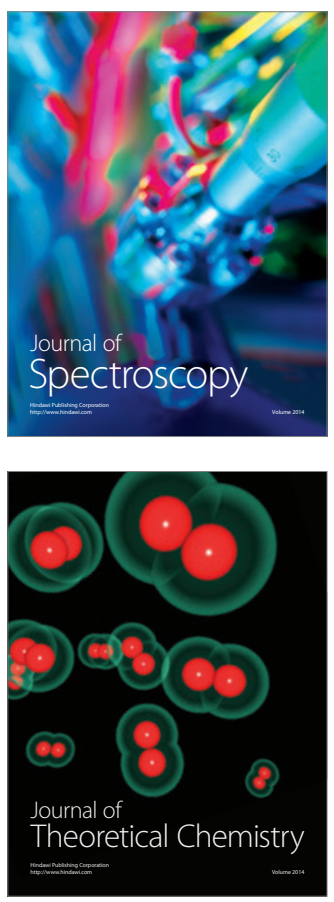
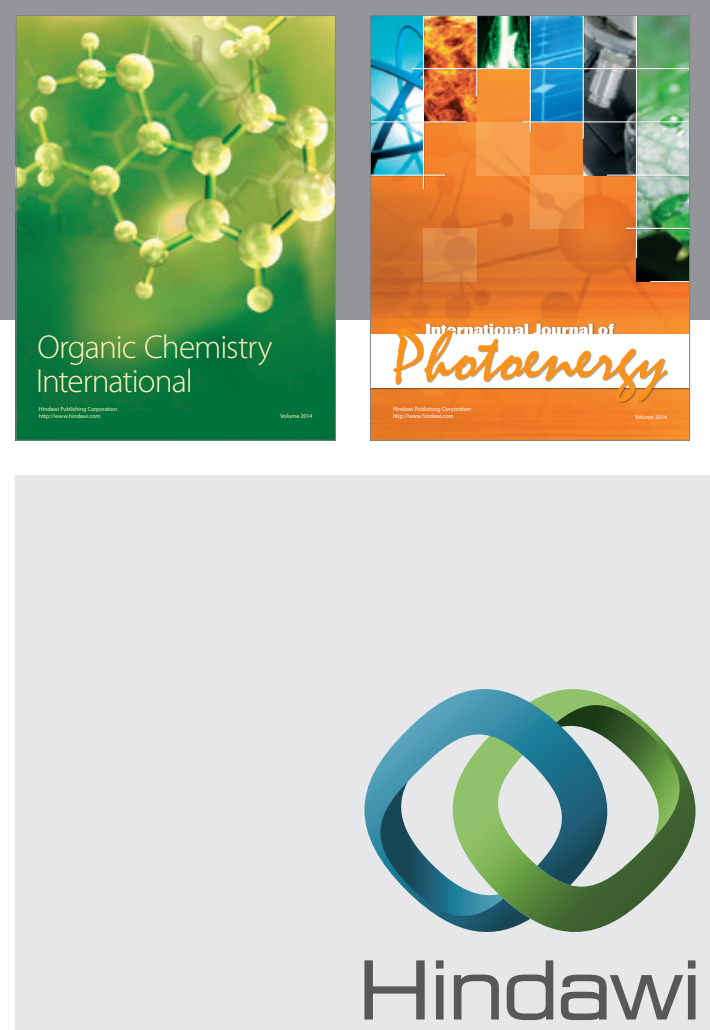

Submit your manuscripts at

http://www.hindawi.com
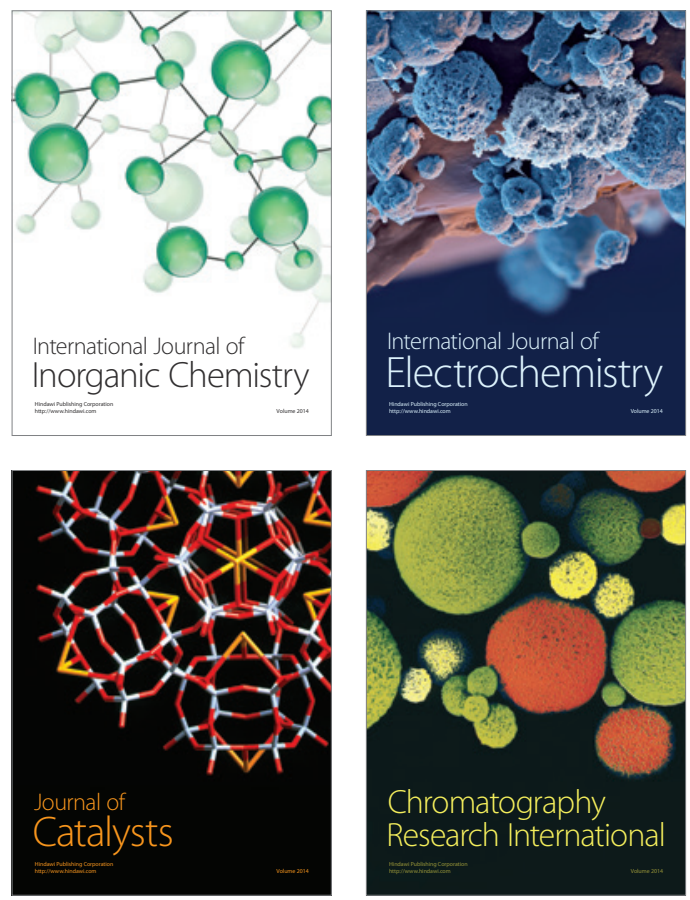
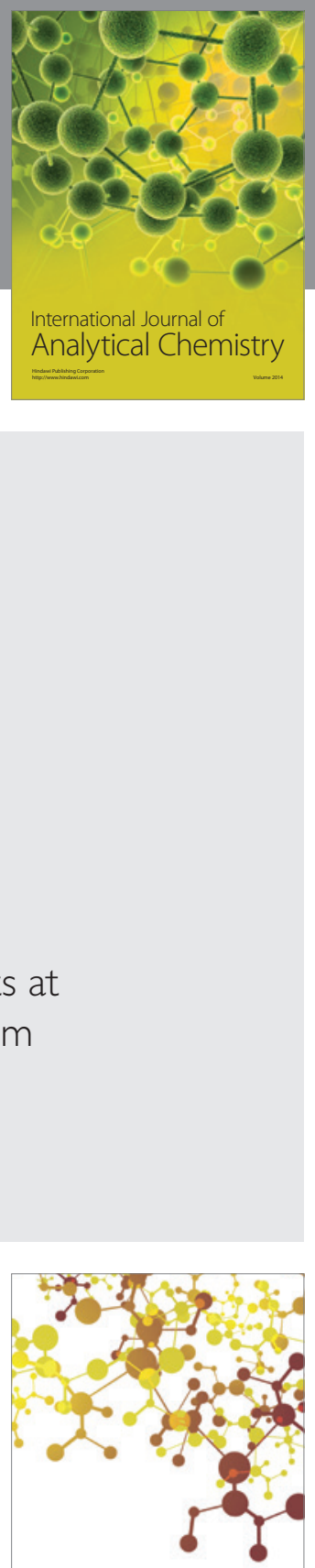

Journal of

Applied Chemistry
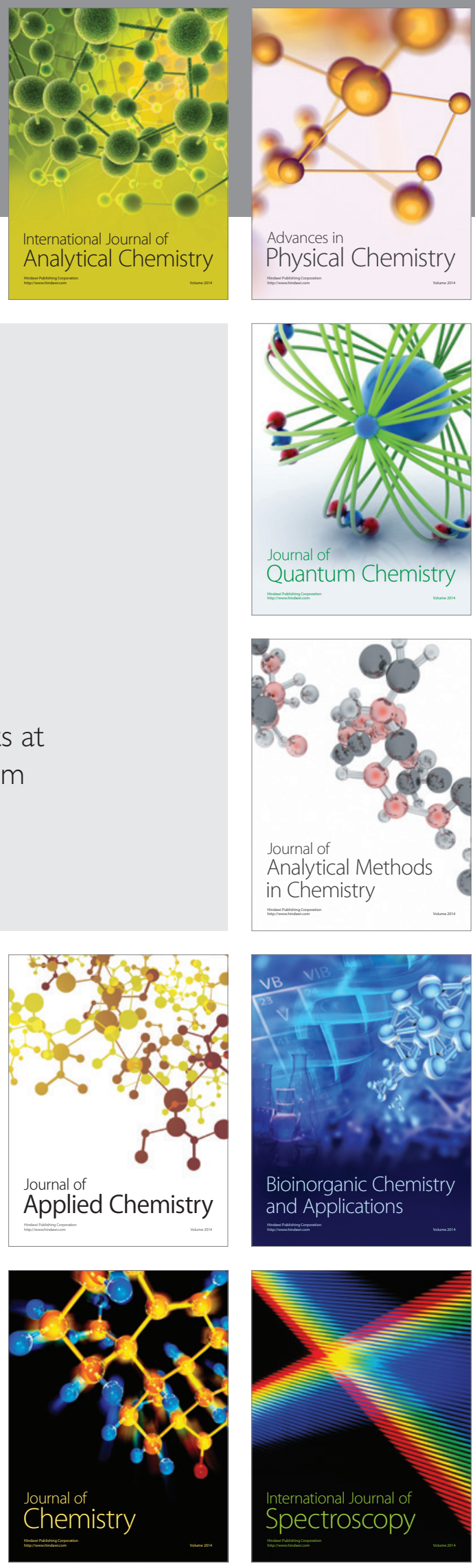